\section{New Vesicle Formation upon Oleate Addition to Preformed Vesicles}

\author{
Suparpun Chungcharoenwattana and Masaharu Ueno*
}

Faculty of Phamaceutical Sciences, Toyama Medical and Pharmaceutical University; 2630 Sugitani, Toyama 930-0194, Japan. Received October 6, 2004; accepted December 7, 2004

\begin{abstract}
The size distribution of new vesicles formed after addition of oleate in different forms to preformed egg yolk phosphatidylcholine (EggPC) vesicles was studied by gel exclusion chromatography. The addition of oleate to preformed vesicles resulted in the formation of new small vesicles. Fission of preformed vesicles incorporated by oleate and partial solubilization of the vesicles by addition of oleate in micellar form were involved in the process of the new small vesicle formation.
\end{abstract}

Key words oleate; phosphatidylcholine; fission; partial solubilization; vesicle formation

Some fatty acids such as decanoic acid and oleic acid can self-assemble into vesicles with sizes ranging from nanometers up to micrometers under defined conditions. ${ }^{1,2)}$ Recently, the effects of preformed vesicles on new vesicle formation has been investigated by addition of oleate micellar solution to the preformed vesicles. Luisi et al. reported that the preformed vesicles not only accelerate the rate of new vesicle formation but also control new vesicles to have sizes similar to their own sizes, ${ }^{3-6)}$ and they called this interesting phenomena "matrix effect". We started to study to clear the mechanism. The results of our study using gel exclusion chromatography showed the presence of new small vesicles after addition of oleate in micellar form to preformed vesicles $^{7,8)}$ in contrast to the results reported by Luisi et al. Therefore, in this report, we study profoundly size distribution of new vesicles upon oleate addition in different forms to preformed egg yolk phosphatidylcholine (EggPC) vesicles.

EggPC and oleate vesicles were prepared by an extrusion technique. An EggPC suspension (6.25 mM or $18.75 \mathrm{~mm}$ ) was passed through a polycarbonate membrane of $400 \mathrm{~nm}$ in pore size and then through a polycarbonate membrane of $200 \mathrm{~nm}$ in pore size, whereas an oleate suspension $(75 \mathrm{~mm}$ or $125 \mathrm{~mm}$ ) was passed through filters of $400 \mathrm{~nm}$ in pore size. The final sizes of EggPC and oleate vesicles as determined by dynamic light scattering were approximately $175 \mathrm{~nm}$ and $260 \mathrm{~nm}$, respectively. Both of EggPC and oleate vesicles were also prepared by sonication, and these sizes were determined by dynamic light scattering to be approximately $50 \mathrm{~nm}$. All samples of vesicles were prepared in $0.1 \mathrm{~m}$ borate buffer containing $150 \mathrm{~mm} \mathrm{NaCl}(\mathrm{pH} 8.5)$. In the case of oleate micellar solution ( $\mathrm{pH} 10.25$ ), sodium oleate was dissolved in purified water. Two hundred microliters of $75 \mathrm{~mm}$ or $125 \mathrm{~mm}$ oleate vesicles with different sizes $(50 \mathrm{~nm}$, $260 \mathrm{~nm}$ ) or oleate micelles was added to $800 \mu 1$ of $18.75 \mathrm{~mm}$ or $6.25 \mathrm{~mm}$ preformed EggPC vesicles $(50 \mathrm{~nm}, 175 \mathrm{~nm})$ followed by stirring for $1 \mathrm{~min}$. Thus, vesicle suspensions with a molar ratio of $1: 1$ or $1: 5$ of EggPC: oleate were prepared. The final $\mathrm{pH}$ after mixing was constant at $\mathrm{pH}$ 8.5. In order to avoid possible partial solubilization by added oleate micelles, the following experiment was performed as follows. One gm of Sephacryl S-1000 gel was saturated with EggPC and oleate. Preformed EggPC vesicles $(50 \mathrm{~nm}, 175 \mathrm{~nm})$ were then added to this saturated gel suspension, and the suspension was shaken in a waterbath at $25^{\circ} \mathrm{C}$ for $1 \mathrm{~d}$.

The vesicle samples, $1 \mathrm{~d}$ after oleate addition, were fractionated on a gel column of Sephacryl S-1000 as described previously. ${ }^{7,8)}$ One-day incubation was confirmed to be sufficient because the elution patterns on gel chromatography of the samples of 1-d incubation were not different from those of 1-h incubation. Gel exclusion profiles of preformed oleate vesicles $(50 \mathrm{~nm}, 260 \mathrm{~nm})$ and preformed EggPC vesicles $(50 \mathrm{~nm}, 175 \mathrm{~nm})$ before mixing are shown in Fig. 1. Each elution pattern of preformed EggPC and oleate vesicles gave one single peak eluted according to size separation.

Figure 2 shows elution profiles of vesicles after an equimolar amount of oleate in vesicular form $(50 \mathrm{~nm}$, $260 \mathrm{~nm})$ was added to preformed EggPC vesicles $(50 \mathrm{~nm}$, $175 \mathrm{~nm}$ ). The elution profiles after adding preformed oleate vesicles $(50 \mathrm{~nm}, 260 \mathrm{~nm})$ to preformed EggPC vesicles $(175 \mathrm{~nm})$ are shown in Figs. 2A, B. Both phospholipid and oleate patterns showed two peaks. The first peak was close to the position of preformed EggPC vesicles and the second peak representing new small vesicles was eluted at $\mathrm{Ve}=12.11-13.37 \mathrm{ml}$ regardless of the size of added oleate vesicles. These results are different from the previously reported results9) of dynamic light scattering, which showed only a single peak corresponding to the size of preformed POPC (1-palmitoyl-2-oleoyl-sn-glycero-3-phosphocholine) vesicles $(70.2 \mathrm{~nm})$ after adding an equimolar amount of oleate vesicles $(30 \mathrm{~nm})$ to the preformed ones. Interestingly, the result of our dynamic light scattering experiment are also similar to those previously reported; that is, the average size of the vesicles after addition of oleate $(50 \mathrm{~nm}$ in diameter) to preformed EggPC vesicles $(175 \mathrm{~nm})$ was $170 \mathrm{~nm}$, which is close to the size of preformed ones. Another experiment in which an equimolar amount of oleate vesicles $(260 \mathrm{~nm})$ was added to preformed EggPC vesicles with a size of $50 \mathrm{~nm}$ was carried out. In this case, as shown in Fig. 2C, only a single peak near that of preformed EggPC vesicles $(50 \mathrm{~nm})$ was observed. In the case of mixing an equimolar amount of oleate micellar solution with preformed EggPC vesicles with a size of $175 \mathrm{~nm}$ (Fig. 3), the elution patterns of both phospholipid and oleate had two peaks similar to the case of addition in

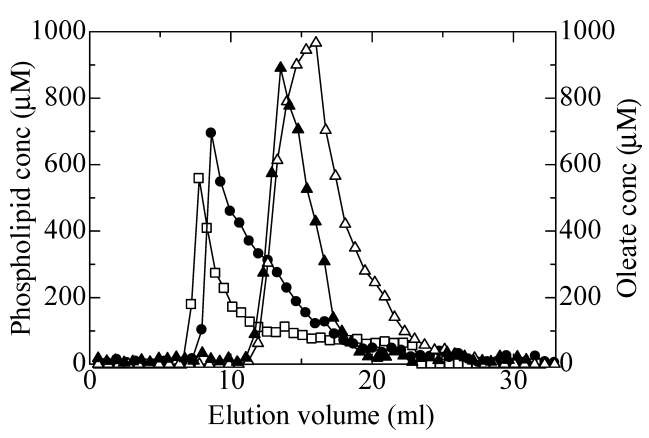

Fig. 1. Gel Exclusion Chromatography of Preformed EggPC and Oleate Vesicles before Mixing These Two Preformed Vesicles Together

$260 \mathrm{~nm}$-preformed oleate vesicles ( $\square-\square), 175 \mathrm{~nm}$-preformed EggPC vesicles $(--), 50 \mathrm{~nm}$-preformed EggPC vesicles (- -$), 50 \mathrm{~nm}$-preformed oleate vesicles $(-\triangle-)$. 

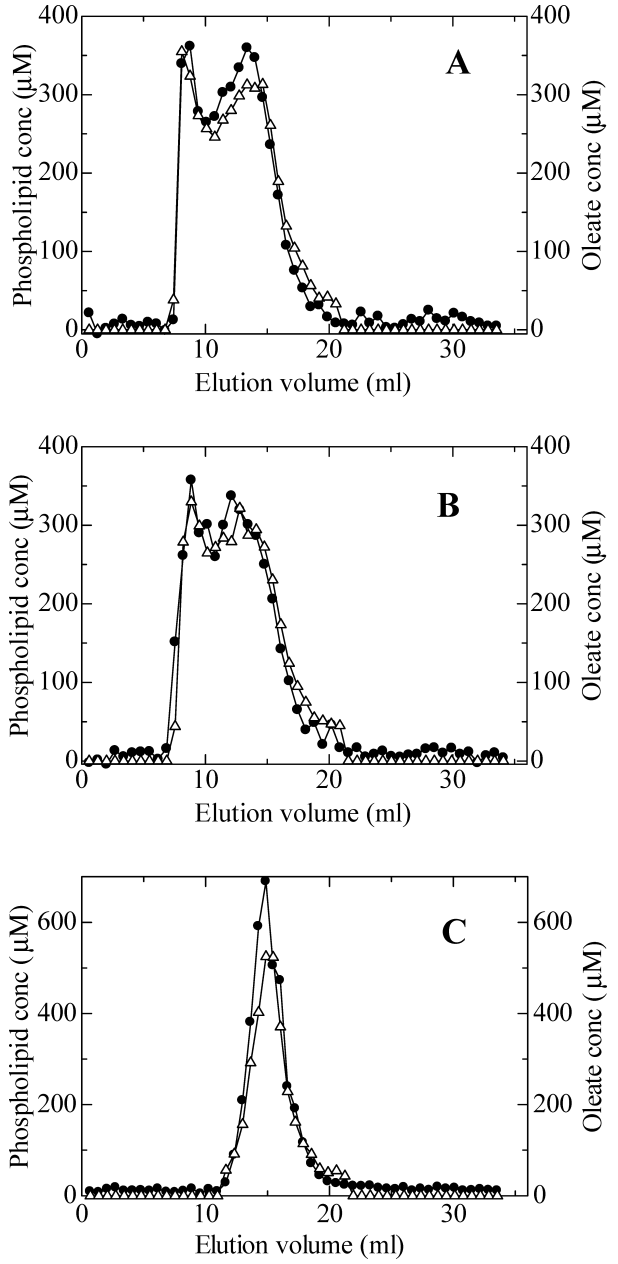

Fig. 2. Gel Elution Patterns of Mixed EggPC/Oleate Vesicles in the Ratio of 1:1 after Addition of Oleate in Vesicular Form to Preformed EggPC Vesicles

(A) Oleate vesicle suspension $(50 \mathrm{~nm})$ was added to preformed EggPC vesicles $(175 \mathrm{~nm})$; (B) oleate vesicle suspension $(260 \mathrm{~nm})$ was added to preformed EggPC vesicles $(175 \mathrm{~nm})$; $(\mathrm{C})$ oleate vesicle suspension $(260 \mathrm{~nm})$ was added to preformed EggPC vesicles $(50 \mathrm{~nm}) .-1-$, phospholipid concentration; $-\triangle-$, oleate concentration.

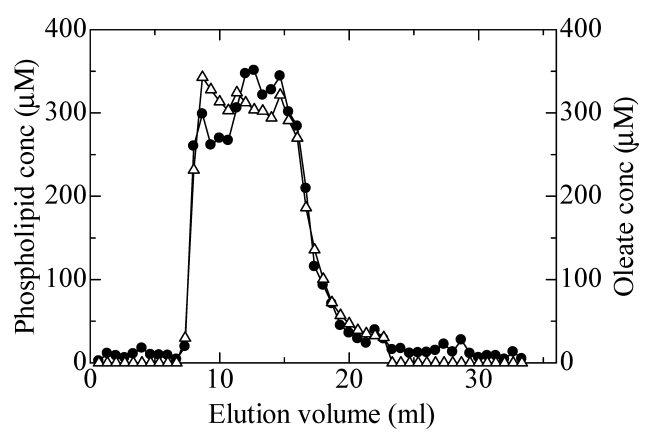

Fig. 3. Gel Elution Patterns of Mixed EggPC/Oleate Vesicles in the Ratio of $1: 1$ after Addition of Oleate Micellar Solution to Preformed EggPC Vesicles $(175 \mathrm{~nm})$

- - phospholipid concentration; $-\triangle$-, oleate concentration.

vesicular form. However, the elution pattern of new small vesicles was slightly broader than the peaks of oleate addition in vesicular form (Figs. 2A, B). This new broader peak was eluted at Ve ranging from 14.67 to $15.33 \mathrm{ml}$ (Fig. 3). The elution profile after oleate micellar addition to preformed EggPC vesicles with a size of $50 \mathrm{~nm}$ has been reported, ${ }^{7,8)}$
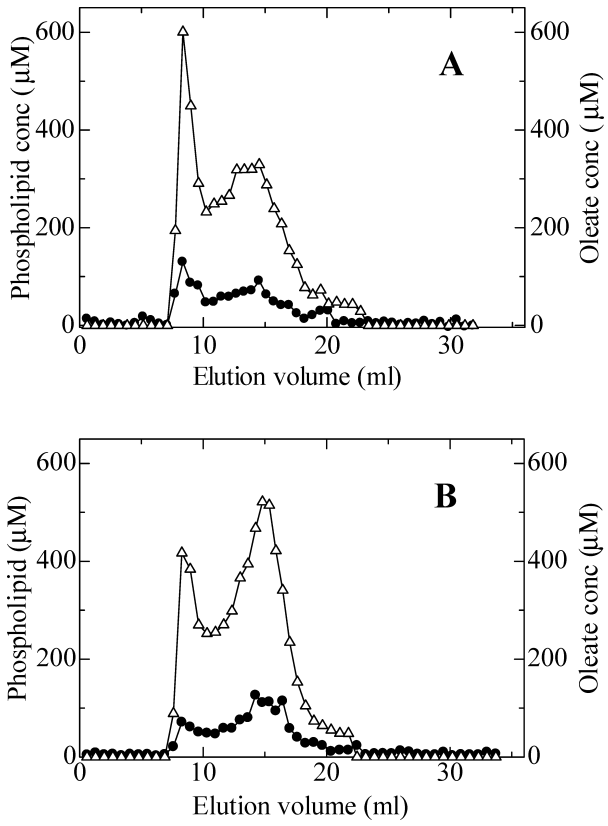

Fig. 4. Gel Exclusion Chromatography of Mixed EggPC/Oleate Vesicles in the Ratio of 1:5 after Addition of two Forms of Oleate to Preformed EggPC Vesicles

(A) Oleate vesicle suspension $(260 \mathrm{~nm})$ was added to preformed EggPC vesicles $(175 \mathrm{~nm})$; (B) oleate micellar solution was added to preformed EggPC vesicles $(175 \mathrm{~nm}) .-1-$, phospholipid concentration; $-\triangle-$, oleate concentration.

and the reported profile is similar to the profile after addition of oleate in vesicular form (Fig. 2C).

The effects of a higher molar concentration of two different forms of oleate (micelles and vesicles) on the formation of new vesicles were also investigated by gel exclusion chromatography, and the results are shown in Fig. 4. The profile after a larger amount $(5: 1)$ of oleate in vesicular form $(260 \mathrm{~nm})$ was added to preformed EggPC vesicles $(175 \mathrm{~nm})$ is presented in Fig. 4A. The profile showed two peaks, one peak of which the elution volume was similar to that of the original peak and a new peak at a larger elution volume $(\mathrm{Ve}=12.70-14.52 \mathrm{ml})$. Addition of oleate in micellar form to preformed EggPC vesicles (Fig. 4B) resulted in a significant decrease in the first peak and a significant increase in the second new peak at Ve in the range of $14.81-15.36 \mathrm{ml}$. Therefore, to eliminate the effect of possible partial solubilization, addition of oleate in the absence of a micellar state to preformed EggPC vesicles with two different sizes $(50 \mathrm{~nm}$, $175 \mathrm{~nm}$ ) was tried as explained previously. The size distributions of these samples are shown in Fig. 5. The addition of an oleate monomer to preformed $\mathrm{EggPC}$ vesicles with a size of $175 \mathrm{~nm}$ (Fig. 5A) resulted in an elution pattern that was similar to the elution pattern (Fig. 4A) obtained after addition of oleate in vesicular form (EggPC: oleate in the ratio of $1: 5$ ). The molar ratio of EggPC and oleate in the former case was also approximately $1: 5$. A single peak was observed in the case of oleate addition in monomer form to preformed EggPC vesicles with a size of $50 \mathrm{~nm}$ (Fig. 5B). When oleate in various forms was added to preformed EggPC vesicles with a size of $175 \mathrm{~nm}$, a new peak at a larger elution volume appeared, indicating formation of new small vesicles. These new small vesicles were difficult to detect by measurement using dynamic light scattering because of the overshadowing by large vesicles. There was also a tendency for vesicular 

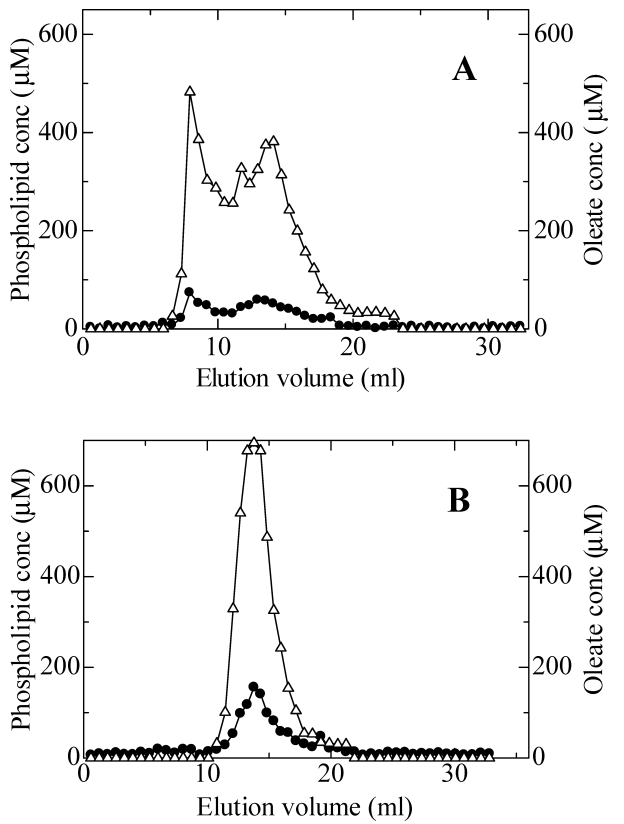

Fig. 5. Gel Elution Patterns of Mixed EggPC/Oleate Vesicles Obtained by Gradual Insertion of Oleate in Monomer Form to Preformed EggPC Vesicle Having Size of $175 \mathrm{~nm}$ (A) and to Preformed EggPC Vesicle Having Size of $50 \mathrm{~nm}(\mathrm{~B})$

——, phospholipid concentration; $-\triangle$ - oleate concentration.

sizes of new small vesicles to be close to $50 \mathrm{~nm}$. Our recent results of transformation of mixed micelles to vesicles showed that the smallest size of mixed EggPC/oleate vesicles was in the range of $45-60 \mathrm{~nm} .{ }^{8)}$ This suggests that the addition of oleate to preformed EggPC vesicles preferred to form small mixed vesicles. In our previous study, ${ }^{8}$ the transformation of mixed EggPC/oleate micelles to mixed vesicles was investigated. The results showed that mixed EggPC/oleate micelles could change into vesicles more rapidly than could mere oleate micelles. These findings suggested that new small vesicles are formed partially by solubilization of preformed vesicles followed by rapid change to new small vesicles after addition of oleate in micellar form. In the present work, the study of size distribution of formed vesicles after oleate addition in vesicular or monomer form could remove the effect of partial solubilization of oleate micelles on new small vesicle formation.

The elution patterns obtained after addition of different amounts of oleate either in vesicular form (Figs. 2A, B, 4A) or in monomer form (Fig. 5A) indicated fission resulting in the formation of new small vesicles. This is different from the previously described mechanism, ${ }^{5,9-11)}$ by which the final size of newly formed vesicles is close to the size of preformed vesicles. Present study showed that the presence of new small vesicles, whose size was different from preformed ones, was explicitly detected by gel filtration, although the average size of newly formed vesicles was close to the size of preformed EggPC vesicles so far as the sizes were analyzed by dynamic light scattering. The fission process caused formation of new small vesicles. The difference between the elution pattern obtained after addition of a larger amount of oleate in micellar form (Fig. 4B) and the elution pattern after addition of the same molar ratio of oleate in either vesicular (Fig. 4A) or monomer form (Fig. 5A) suggested that some of the new small vesicles were formed by partial solubilization. Furthermore, the results showed that the larger the amount of oleate micelles is, the greater is the effect of partial solubilization. In the case of preformed EggPC vesicles with a size of $50 \mathrm{~nm}$, there was no considerable difference after addition of oleate in various forms (monomer, micelle, vesicle) to preformed vesicles, because of the similar size of newly formed vesicles to preformed ones.

In conclusion, the addition of oleate in three forms (monomer, micelle and vesicle) to preformed EggPC vesicles caused the formation of new small vesicles in addition to oleate-containing vesicles with a peak position close to that of preformed vesicles. Gel exclusion chromatography showed that two mechanisms, fission and partial solubilization, were involved in the formation of new small vesicle, when oleate in micellar form was added to preformed vesicle suspension.

\section{References}

1) Walde P., Wick R., Fresta M., Mangone A., Luisi P. L., J. Am. Chem. Soc., 116, 11649-11654 (1994).

2) Apel C. L., Deamer D. W., Mautner M. N., Biochim. Biophys. Acta, 1559, $1-9$ (2002).

3) Blochliger E., Blocher M., Walde P., Luisi P. L., J. Phys. Chem. B, 102, 10383-10390 (1998).

4) Lonchin S., Luisi P. L., Walde P., Robinson B. H., J. Phys. Chem. B, 103, 10910-10916 (1999).

5) Berclaz N., Blochliger E., Muller M., Luisi P. L., J. Phys. Chem. B, 105, 1065-1071 (2001).

6) Rasi S., Mavelli F., Luisi P. L., J. Phys. Chem. B, 107, 14068-14076 (2003).

7) Chungcharoenwattana S., Ueno M., Chem. Pharm. Bull., 52, 10581062 (2004).

8) Chungcharoenwattana S., Ueno M., 26th Annual Meeting of Japan Membrane Society, Tokyo, on May 2004.

9) Cheng Z., Luisi P. L., J. Phys. Chem. B, 107, 10940-10945 (2003).

10) Berclaz N., Muller M., Walde P., Luisi, P. L., J. Phys. Chem. B, 105, 1056-1064 (2001).

11) Luisi P. L., Stano P., Rasi S., Mavelli F., Artif. Life, 10, 297-308 (2004). 